\title{
Da eloquência dos frontispícios: discurso político sobre a presença holandesa em Pernambuco'
}

From the frontispieces' eloquence: political discourse on the Dutch presence in Pernambuco

hitps://doi.org/10.1590/1982-02672020v28e16

\section{JORGE VICTOR DE ARAÚJO SOUZA²}

https:/ / orcid.org/0000-0002-5026-7120

Universidade Federal do Rio de Janeiro/Rio de Janeiro, RJ, Brasil

\author{
LUIS HENRIQUE SOUZA DOS SANTOS 3 \\ https:/ / orcid.org/0000-0002-2568-0589 \\ Universidade Federal do Rio de Janeiro/ Rio de Janeiro, RJ, Brasil
}

RESUMO: O presente artigo tem por objetivo principal discutir as relações estabelecidas entre os frontispícios e as intencionalidades dos livros nos quais foram impressos, nas obras Nova Lusitânia (1675), de Francisco de Brito Freyre, e Rerum per Octennium in Brasilia (1647), de Gaspar van Baerle. Abordamos estes frontispícios contando com a identificação dos atributos, dos personagens e dos espaços representados pelos gravadores de tais imagens, assim como seus conteúdos textuais. Tomando como ponto de partida os aspectos imagéticos presentes nas folhas de rosto dos livros mencionados, buscamos traçar os padrões de intencionalidade presentes nos livros enquanto discursos políticos. Discute-se como Van Baerle acessa os símbolos a sua disposição para enaltecer os feitos do Conde de Nassau em Pernambuco, da mesma forma que Brito Freyre opera com referências clássicas e constrói uma narrativa heroica de sua própria experiência contra o domínio holandês na América portuguesa.

\begin{abstract}
1. Agradecemos aos colegas do Laboratório de Teoria e de História das Mídias Medievais (LATHIMM) da Universidade de São Paulo (USP) e do Laboratório Sacralidades do Instituto de História da Universidade Federal do Rio de Janeiro (UFRJ) pelo diálogo e sugestões em momentos distintos da pesquisa que gerou este artigo.

2. Professor Adjunto de História da América no Instituto de História da Universidade Federal do Rio de Janeiro (UFRJ). E-mail: <jvictoraraujos@gmail.com>

3. Doutorando em História pelo Programa de Pós-Graduação em História Social da UFRJ. E-mail: $<$ luissantoshenrique@ yahoo.com.br>
\end{abstract}


PALAVRAS-CHAVE: História e Imagem. Holandeses no Brasil. Pernambuco. Francisco de Brito Freyre. Gaspar van Baerle.

ABSTRACT: The main point of this paper is to discuss the relations established between the frontispieces and the intentionality of the books in which they were printed, in the works Nova Lusitânia (1675) of Francisco de Brito Freyre, and Rerum per Octennium in Brasilia (1647) of Gaspar Van Baerle. We aproach these frontispieces counting with the identification of the attributes, characters and spaces represented by the gravers of such images, as their textual contents. Taking as a starting point the imagery aspects presented on the cover pages of the mentioned books, we seek to trace the patters of intentions of the books and their respective engravings as political discourses. In this way, not only the images but also the works themselves are connected. It discusses how Gaspar Van Baerle access the symbols at his disposal to praise the deeds of the Count of Nassau at Pernambuco; otherwise, Francisco de Brito Freyre operates with classical references and build a heroic narrative of his own experience against the Dutch domain in Portuguese America.

KEYWORDS: History and Image. Dutch in Brazil. Pernambuco. Francisco de Brito Freyre. Gaspar van Baerle. 
Não há um estudo histórico que tenha reunido os principais frontispícios de livros sobre o Brasil do século XVII. Com exceções, tais imagens são apresentadas dispersas e apenas como ilustrações de artigos. Em que pese terem sido produzidas para livros que tiveram distintas condições de edição e diferentes intencionalidades e pertencimentos ao discurso político à época, acreditamos que uma análise detida do conjunto apontará as formas pelas quais, no século $X V I I$, criou-se uma eloquência sobre a expansão ultramarina, forjando alegorias que abriam os mais importantes livros sobre o Brasil. Essa modalidade de produção de imagens, e, atrelada a ela, a escrita, teve seu auge no século XVII, com um considerável declínio e posterior desaparecimento no século XVIII.

Nosso esforço foi no sentido de identificarmos e apresentarmos dados sobre os gravadores, assim como investigarmos as iconografias presentes em tais frontispícios, contando com a identificação dos atributos, dos personagens e dos espaços representados, seguindo as particularidades do discurso político enunciadas por Diogo Ramada Curto. ${ }^{4}$ Neste artigo, realizaremos a comparação entre imagens que foram produzidas para livros sobre o Brasil, mormente os de dois autores que escreveram sobre as relações entre holandeses e ibéricos, levando em consideração seus períodos de produção e publicação. Durante a pesquisa, fomos norteados pela seguinte questão: em que medida tais imagens são significativas para uma melhor compreensão das relações entre a produção discursiva e a difusão de conhecimentos a respeito do Novo Mundo? Ou seja, como as imagens estão inseridas na lógica do discurso político moderno, principalmente no choque entre as descrições dos feitos de portugueses ou holandeses na América?

Uma vez que o gênero estudado não pertence tão somente ao domínio da escrita, bem como ao de imagens, cabem reflexões mais atentas sobre as particularidades das agências dessas imagens. Sobre os significados de tais imagens, levamos em consideração as reflexões de Roy Wagner, para quem "Só podemos definir um elemento simbólico, ou atribuir prioridades às suas várias associações convencionais, com base na (suposta) significância relativa dos contextos do qual ele participa." ${ }^{5} \bigcirc$ antropólogo americano conclui que "o significado é, pois, produto das relações, e as propriedades significativas de uma definição são resultados do ato de relacionar tanto quanto as de qualquer outro constructo expressivo". ${ }^{6}$ Cabe então ao historiador esclarecer as possíveis relações em que um dado documento foi produzido. Entretanto, de forma dialética, ao estabelecer novas relações entre os documentos, os historiadores podem melhor esclarecer determinados significados. No caso de 
7. Rancière (2012, p. 16).

8. Baxandall (2006, p. 47).

9. Didi-Huberman (2013, p. 33).

10. Alberti (2004, p. 31). documentos imagéticos, essa premissa torna-se mais pertinente por conta da rede de referências em que as imagens estão inseridas e de que são parte constituinte, sobretudo as de cunho alegórico, como comumente são as dos livros aqui apresentados. No caso dos frontispícios, observa-se ainda uma particularidade, pois são imagens que sempre possuem relação direta e intrínseca com a escrita, seja com faixas que as acompanham, seja com os títulos e demais elementos, seja, enfim, com o conteúdo geral da obra. Nesse sentido, cabe atentar que se tratando de imagens há um regime comum que é o que relaciona o dizível com o visível, conforme salientou Jacques Rancière.? Portanto, pode-se considerar que para os frontispícios tal regime é inescapável. Abordamos tais imagens enquanto fronteiras, espaços entre o leitor e o conteúdo geral da obra.

Assim como o seu parente arquitetônico, o frontispício de um livro foi construído para ser atravessado. É local de passagem e de memória. Acompanhando o pensamento do historiador da arte Michael Baxandall, partimos do pressuposto de que estudamos "um objeto que foi produzido de modo intencional, e não um subproduto documental de uma atividade". ${ }^{8}$ Isso significa dizer que faremos um esforço para identificarmos as possíveis marcas de intencionalidade presentes nas imagens e nos escritos que as acompanham. Tais marcas vão ao encontro da reflexão efetuada pelo filósofo Georges Didi-Huberman sobre a obra do historiador da arte Aby Warburg: "Uma imagem, toda imagem, resulta dos movimentos provisoriamente sedimentados ou cristalizados nela."

No entanto, pensarmos em "movimentos sedimentados" não é igual a dizer que a imagem não produz ela mesma movimentos. A imagem há muito possui particularidades nas relações com quem as observa. Em 1435, por exemplo, o genovês Leon Batista Alberti, em seu famoso Da pintura, salientou como imagens podiam agir sobre os sentidos do observador:

Em primeiro lugar, todos os corpos devem movimentar-se de acordo com o que está disposto na história. Agrada-me que nela haja alguém que nos advirta e nos mostre o que está ocorrendo, ou nos acene com a mão para ver, ou ameace com a fisionomia irritada e com os olhos perturbados, para que alguém se aproxime, ou aponte para algum perigo ou coisa admirável, ou nos convide a chorar junto com ele ou a rir. ${ }^{10}$

Este "convite da imagem" é o que contemporaneamente denominamos por seu "agenciamento". Se ela de fato convidava a chorar e a rir, como afirmou Alberti, é mais do que lógico inferirmos que convidava também a ter raiva, a tomar partido em uma situação ou a refletir sobre uma determinada questão. A imagem em um livro era antes de tudo um convite à leitura. E, nesse sentido, concordamos com a afirmação de Leopold Waizbort, para quem: 
A análise das imagens precisa incorporar o complexo das dimensões sociais e históricas em seu sentido mais amplo, situando-se para além dos mourões limítrofes de toda e qualquer disciplina. Imagens conectam-se a práticas, a materiais, a ideias, e sua dimensão simbólica está situada nas confluências desses domínios. ${ }^{11}$

As imagens em livros acabam por requerer um esforço interdisciplinar por parte do pesquisador. É dessa forma que nos debruçaremos sobre os frontispícios de duas obras da segunda metade do século XVII: a Nova Lusitânia, História da Guerra Brasilia, de Francisco de Brito Freyre (figura 1), e Rerum per Octennium in Brasilia, de Gaspar van Baerle (figura 3).

Para encerrarmos esta introdução, cabe salientar que não usamos neste artigo a noção dedutiva de "barroco", tão comum para designar um conjunto de dispositivos do discurso seiscentista. Nesse ponto, estamos de acordo com João Adolfo Hansen, para quem o termo diz mais a respeito das preocupações estéticas de críticos do século XIX do que sobre as condições de produção de obras do século XVII. ${ }^{12}$ No entanto, ainda seguindo os passos de Hansen, entendemos o frontispício enquanto uma alegoria, ou seja, como "procedimento retórico" utilizado para afirmar ou demonstrar um pensamento. ${ }^{13} \mathrm{E}$, nesse sentido, podemos afirmar, como Angus Fletcher, que as alegorias eram usadas em intencionalidades de controle político. ${ }^{14}$

\section{O ROSTO DE UMA OBRA}

Por vezes, frontispícios são analisados na perspectiva formalista. Foi o que realizou José Luis Herrera Morillas ao pesquisar o fundo antigo digitalizado da coleção da Universidade de Sevilha. Sua classificação levou em consideração 84 livros que possuem ilustrações em seus frontispícios. Seu estudo é dedicado às categorizações estilísticas, e delas nos interessa a relação entre a arquitetura e as imagens das gravuras. Segundo Herrera Morillas, os elementos figurativos e iconográficos estão mais presentes em "frontispicios de planchas que en los de orlas arquitetónicas". ${ }^{15}$

Como veremos de forma detida mais adiante, um frontispício era o rosto de uma obra. Entendê-lo era, então, como interpretar os sinais fisionômicos para se chegar ao humor. No entanto, o mais comum era a sua analogia com uma construção arquitetônica. Na primeira metade do século XVIII, o padre francês Raphael Bluteau, em seu dicionário da língua portuguesa, definiu as folhas ilustradas que abrem um livro como algo comum ao linguajar do arquiteto "que arremata a obra de um pórtico". ${ }^{16}$ Antes de indicar a existência de uma relação do campo semântico do
11. Waizbort (2015, p. 20)

12. Cf. Hansen (2001).

13. Cf. Hansen (1986).

14. Fletcher (1990. p. 324).

15. Herrera Morillas (2015, p. 11).

16. Bluteau (1713, p. 220) 
17. Galhegos (1635, estrofe 33).

18. Um bom exemplo da relação entre as imagens e a política nos frontispícios nos seiscentos. Cf. Sanchez (2018).

19. Cf. Redondi (1991, fig. 1). 20. Ginzburg (2014, p. 28). termo com o objeto livro, Bluteau cita ainda um trecho do longo poema de Manuel de Galhegos (1597-1665) intitulado "Templo da Memória", publicado em 1635, com dedicatória ao Duque de Bragança. $O$ verso completo, que enfatiza os feitos de uma família, com destaque para o personagem Guilherme Peres de Guzmão que combateu os mouros na Batalha de Tolosa no ano de 1212, é o que segue:

\footnotetext{
Quem vos pintara armado de Diamante

No frontispício diáfano do Oriente

Porque visto do mundo esse semblante

Vos venerasse a mais remota gente.

E porque apar do sol, de luz vestido,

Cada dia vos vísseis aplaudido. ${ }^{17}$
}

Mesmo não se tratando de um livro propriamente, e sim de uma alegoria, a relação estabelecida pelo dicionarista entre frontispício, memória e fama ao escolher esse trecho de um poema seiscentista não foi ao acaso. Desde um século antes do dicionário de Bluteau ser publicado, as páginas dos livros já expunham imagens que faziam tal operação, por vezes ostentando o retrato do autor ou de quem tivesse relação direta com a obra. Uma das intencionalidades de um frontispício era ampliar a fama. Mas a fama de quem ou do que, e como?

Pelo menos nos últimos vinte anos, os frontispícios têm despertado a atenção dos historiadores, como repertório de indícios significativos. ${ }^{18}$ Foi o que realizou Pietro Redondi em sua análise sobre a condenação de Galileu. A estampa de II Saggiatore, feita pelo gravador Francesco Villamena (1564-1624), salienta a importância da matemática no pensamento galileano, ao apresentar uma alegoria dessa disciplina ao lado de uma da física natural. Consta que em 1623 o padre jesuíta Orazio Grazzi, oponente de Galileu na polêmica acerca dos cometas, perdeu a cor diante do frontispício, momentos antes de comprar a obra. O livro ostentava símbolos da patronagem: o pontífice, a família Médici e o Linceu. Em carta, Galileu comentou as suas impressões da estampa: "vi o frontispício do Saggiatore, que me foi enviado pelo senhor Stelluti, o qual me agradou muito, e se entre as duas palavras Astronomica filosofica se acrescentasse um pequeno " $\mathrm{e}$ " maiúsculo corrigir-se-ia esse pequeno erro de impressão". ${ }^{19}$

Em outro livro fundamental para o pensamento políitico do século XVII também é perceptível que o frontispício cumpre com as intencionalidades dos envolvidos em sua produção. Trata-se do Leviatã (1651), obra de Thomas Hobbes. Como salienta Carlo Ginzburg: "O frontispício do Leviatã representa o Deus mortal, o Estado, com a espada numa das mãos e o báculo na outra." 20 E o historiador vai além, apontando 
que a estampa apresenta uma passagem bíblica retirada de Jó 41 : "não existe poder sobre a terra comparável a ele". Levando Ginzburg a concluir que Hobbes pensara na origem paralela da religião e do Estado, tendo o medo como o epicentro.

Para Horst Bredekamp, o frontispício do Leviatã é um componente fundamental da obra, e não apenas mera decoração para a folha de rosto. Bredekamp sustenta que Hobbes realizou um verdadeiro programa iconográfico muito bem definido. ${ }^{21} \bigcirc$ especialista em História do Pensamento Político Moderno Quentin Skinner, ao estudar o problema da liberdade em Hobbes, foi ao encontro de Bredekamp, e salientou a existência, no século XVII, de uma tradição humanista que cultivava a eloquência visual como modus operandi nos jogos políticos. ${ }^{22}$ Em outras palavras, tudo indica que na ldade Moderna havia uma linguagem política que fazia uso de recursos visuais em sua comunicação.

No Brasil, os frontispícios mais expressivos da cultura política moderna dizem respeito ao período de ocupação holandesa, levando-nos a afirmar que houve uma significativa "batalha de imagens" entre as nações.

\section{NOVA LUSITÂNIA}

Francisco de Brito Freyre nasceu aproximadamente em 1625 na vila portuguesa de Coruche e morreu em 1692 em Lisboa. ${ }^{23}$ José Antônio Gonsalves de Mello, em ligeira biografia de Brito Freyre, menciona os sucessos deste militar português que serviu, majoritariamente, no Atlântico lusitano. ${ }^{24} \mathrm{Em} 1653$, foi nomeado almirante da Companhia Geral de Comércio do Estado do Brasil e, no ano seguinte, alcançou o posto de general da frota da mesma companhia. Esta teve importante atuação nas negociações e conflitos contra os holandeses que regiam Pernambuco e as capitanias do Norte.

Tal importância se verifica na atuação de Brito Freyre nas batalhas contra os batavos, ao lado de figuras como João Fernandes Vieira, André Vidal de Negreiros, Francisco Barreto de Meneses, Felipe Camarão e muitos outros militares de destaque. Foi, posteriormente, nomeado a cargos de governo, como à Praça de Jerumenha, em 1658, e à própria capitania de Pernambuco entre os anos de 1661 e 1664. Foi encarregado, em 1669, de transportar o deposto rei D. Afonso VI à llha Terceira, função a qual se recusou e enfrentou o cárcere, onde supostamente escreveu a obra Nova Lusitânia, História da Guerra Brasílica. ${ }^{25}$
21. Cf. Bredekamp (2007).

22. Cf. Skinner (2010).

23. Optamos pela utilização da grafia do nome de Francisco de Brito Freyre seguindo a escrita da publicação de sua obra em 1675.

24. Cf. Mello (1977).

25. Ibid. 
26. Cf. Martins (2014).

27. Este trecho se encontra na seção "O impressor aos que lerem" de Freyre (1675).

28. Cf. Ericeira (1679).

29. Para um estudo sobre as cortes 1668 , cf. Xavier (1998).

30. Freyre (Op. Cit., páginas não numeradas, a2).
Deve-se ressaltar a publicação anexa à Nova Lusitânia, a relação da Viage da Armada da Companhia do Comercio, e Frotas do Estado do Brasil, livro anteriormente publicado em 1657 e que descreve acontecimentos do ano de 1655. A iniciativa de impressão, ao que indica o impressor João Galram ${ }^{26}$ - ou Galrão -, veio deste próprio, a fim de colocar em papel uma edição completa de Nova Lusitânia, para a qual mandou, inclusive, "vir de Amstradão, letras novas de toda a sorte, só a fim de imprimir no modo mais decente, hum Livro tão esperado da curiosidade universal". ${ }^{27}$ Este impressor, inclusive, foi o primeiro a trazer a lume, alguns anos depois, a célebre obra História de Portugal Restaurado do Conde de Ericeira. ${ }^{28}$

Vindo a publicar em 1675, a Nova Lusitânia, Francisco de Brito Freyre narra aquilo que vivenciou nos campos de batalha e as glórias portuguesas contra os holandeses na restauração de Pernambuco. O livro é dedicado a D. Teodósio de Bragança (1634-1653), que tinha por título "Príncipe de Portugal e do Brasil", dado por seu pai, D. João IV, em 1645. Como mencionado anteriormente, Brito Freyre compôs sua História quando da prisão após a deposição de D. Afonso VI e da posse de D. Pedro II como príncipe regente de Portugal. 29 Dedicar sua obra a um príncipe morto há 22 anos vale, no mínimo, a desconfiança de que suas palavras na dedicatória não fossem direcionadas unicamente a D. Teodósio. Passa, pois, sua atenção à monarquia:

E pois que espirando este objecto verdadeiro, da saudade publica, pareceu que espirava a Lusitana Monarchia, \& chorando-o a elle, \& a ella, em huã mesma sepultura, por aquelle golpe preciso, não cortar a nossas prosperidades, as victorias destinadas a seus merecimentos, se trocou a imaginada desgraça, em tão ditosa sorte, que descançamos com a nova paz, das passadas molestias.

O tema encomiástico, assim, está na recente independência e liberdade da Coroa portuguesa da união a Castela. Com D. Afonso preso no Palácio de Sintra, a dedicatória concentra sua homenagem no irmão falecido da dinastia Bragança para, logo depois, passar às glórias do atual príncipe regente: "Resta agora, ó Alma gloriosissima, solicitardes da Piedade Divina, a conservação das presentes felicidades, no felicíssimo Principe, \& amado Senhor nosso DOM PEDRO". 30

Em seu aviso ao leitor, Freyre faz uma inusitada comparação entre historiadores e soldados. Os primeiros estariam mais para ouvir, como mestres da eloquência, enquanto os segundos deveriam ser ouvidos, "como testemunhas da verdade". Claro que, como combatente, Freyre se coloca ao lado dos que narram fatos verdadeiros. Sua iniciativa de escritor, assim, incorre em três motivos que 
mesclam a arte retórica, estratégia militar e filiação política: a necessidade de escrever Histórias sobre as Guerras contra Flandres; o mister de ouvir os soldados em matérias que lhe são caras; e o bom uso de seu ócio para engrandecer as notícias de vitórias portuguesas contra os inimigos. ${ }^{31}$

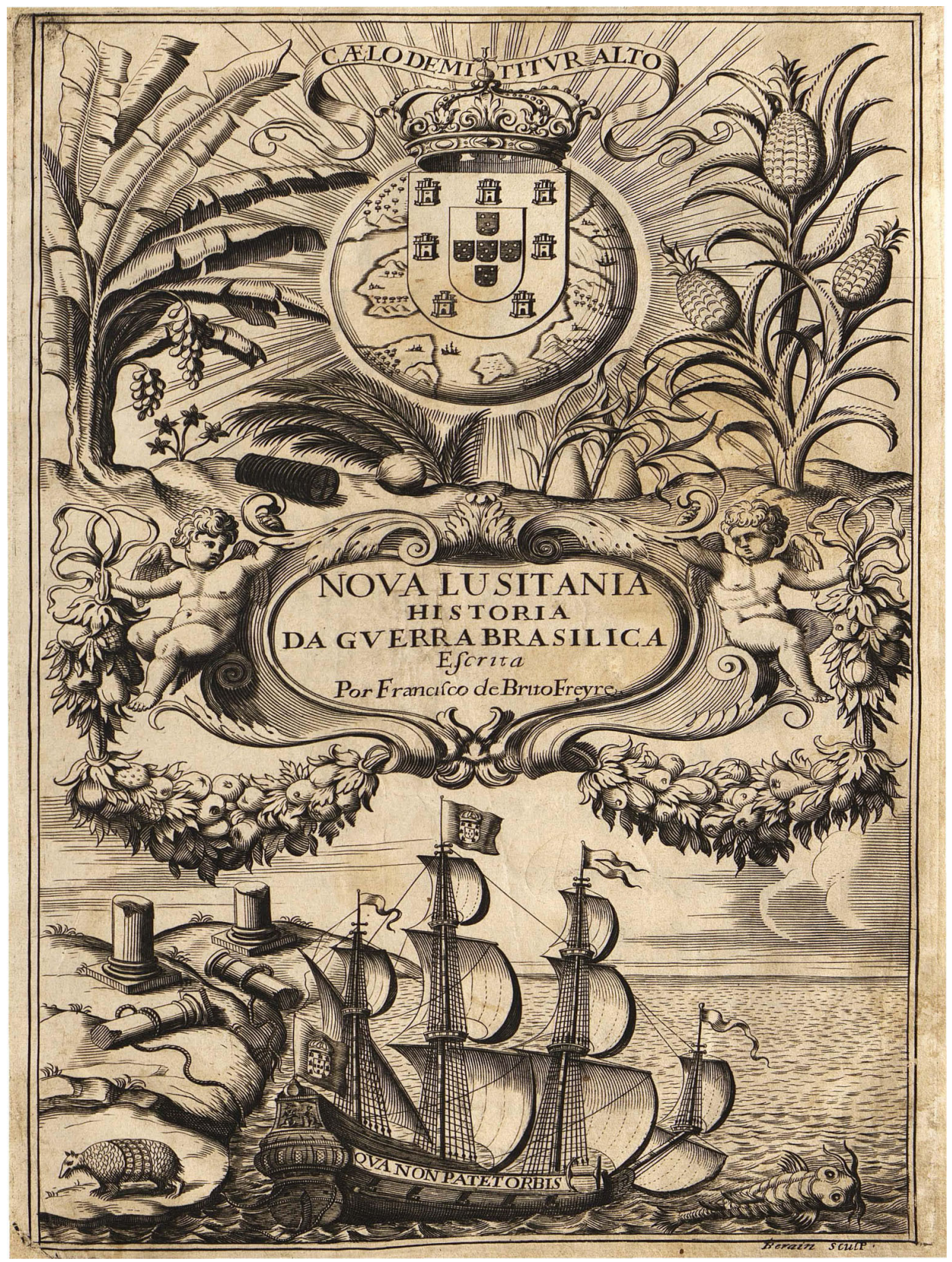

Figura 1 - Frontispício do livro Nova Lusitânia, de Francisco de Brito Freyre. ${ }^{32}$ 
Já na advertência da obra, Freyre salienta um tópico conhecido ao falar do nome Brasil, pois diz que a perda do topos Santa Cruz foi por conta de um irreligioso esquecimento. É nesse ponto que ele explica claramente a opção pelo nome de sua obra, o que, em nossa interpretação, possui uma relação intrínseca com toda a imagem do frontispício, sobretudo ao relacionarmos sua explicação ao mote de uma faixa que encima a coroa lusitana. Em suas palavras, as denominações da região sob o controle luso são assim atribuídas:

[...] o de América, só em parte lhes toca, o de Índias, no domínio de Castella he mais próprio e o de Brasil menos decoroso: segundo a voz das outras nações; e povoando-se da portuguesa uma região tamanha do Novo Mundo, especialmente the chamaremos (como já chamam alguns) a Nova Lusitânia. ${ }^{33}$

Cabe salientar que "Nova Lusitania" é o nome pelo qual a capitania de Pernambuco era chamada em parte do século XVI. Freyre faz então com que o antigo nome do território, naquele momento recém-conquistado aos holandeses, seja usado de forma ampliada para toda a região sobre domínio luso. Entretanto, ele parece não ter levado em consideração as histórias emaranhadas dos reinos da Península lbérica que o termo Lusitânia mobilizava. O que lhe importava era pensar na criação de uma identidade comum, sobretudo antiflamenga (figura 2). O segundo parágrafo da advertência completa esse sentido:

E porque na estampa que faz rosto ao nosso argumento, parecera menos vulgar a letra Qua non patet orbis, adverte-se que o Conde João Mauricio de Nassau, sendo o General do Brasil das armas holandesas trazia por empresa nas suas (como ainda se vê em todas as obras publicas dos anos que governou as capitanias do Norte; tão ostentosamente escritos, na avultada historia de Gaspar Barleu) Qua patet orbis. Pelo que, (deixando as circunstâncias que os leitores por si mesmos alcançarão facilmente) acrescentamos ao mote do Conde, o non, que o imperador Carlos Quinto, tirou ao Non Plus Ultra das colunas de Hércules. A que as antigas naus indissoluvelmente prenderam tantos séculos as amarras: que rotas pela feliz ousadia dos portugueses dilataram o Universo com terras incógnitas, por mares não sulcados. ${ }^{34}$

A operação realizada por Brito Freyre é, além de retórica, estratégica. O lema do Príncipe João Maurício de Nassau $(1604-1679)^{35}$ e de sua empreitada à frente das Capitanias do Norte era qua patet orbis - grosso modo, "até onde houver mundo". A essa epígrafe, Freyre adiciona a negativa, qua non patet orbis, impõe limites ao orbis holandês, tal como haviam feito os portugueses com suas armas ao reconquistar Pernambuco. Tais limites, contudo, ao tomarmos as colunas de Hércules quebradas no 
frontispício da Nova Lusitânia, não se impunham à marinha lusa. Entendemos as narrativas que descrevem as imagens de ambos os frontispícios aqui analisados como sendo ekphrasis, ou seja, como preceito retórico que descreve ações, lugares, pessoas, eventos, paisagens etc., e que possui como finalidade "pôr tais coisas diante dos olhos" do ouvinte/leitor. Outrossim, acompanhamos as deduções de Adolfo Hansen sobre essa tipologia de enunciado originária na antiguidade: ela traz clareza e evidência, assim como quase produz a visão partindo do que se ouve. ${ }^{36}$

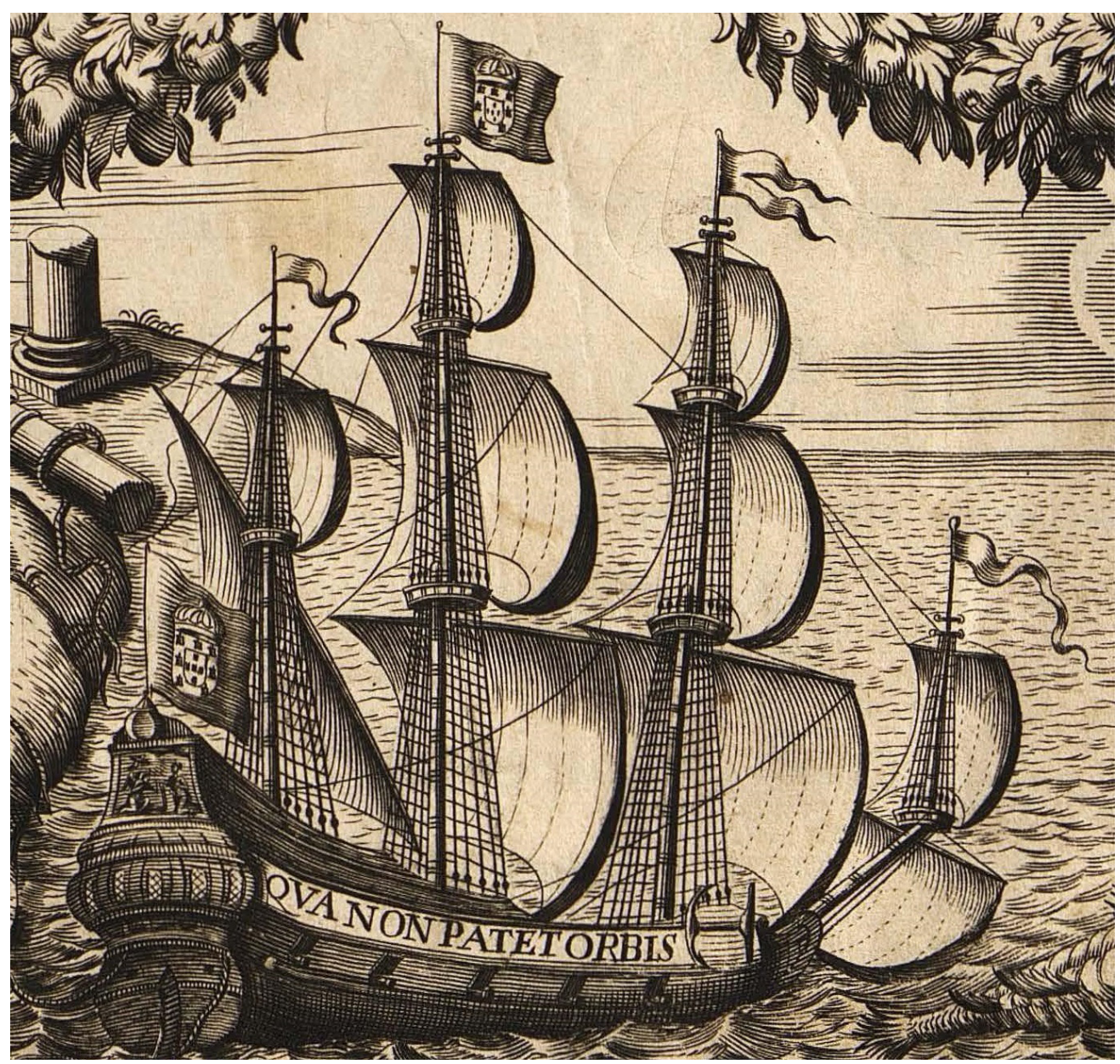

Figura 2 - Detalhe da embarcação no frontispício do livro Nova Lusitânia. ${ }^{37}$

Poucas são as vezes que encontramos uma indicação tão explícita quanto ao uso de uma imagem em um frontispício. Brito Freyre menciona que a gravura faz "rosto" ao seu argumento. Lembremos que frontispícios também eram chamados de páginas de rosto, derivando para nossa atual folha de rosto. A relação com uma parte do corpo humano também aparece na definição de Bluteau, que afirma que
36. Cf. Hansen (2019).

37. Freyre (Op. Cit., páginas não numeradas, b3). 
38. Bluteau (Op. Cit., p. 220).

39. Covarrubias y Orozco (1673, p. 16)

40. Reconhecer esta relação, não é tarefa nova. Varnhagen (1872), o Barão de Porto Seguro, faz uma breve consideração sobre o livro de Francisco de Brito Freyre como uma narração tendenciosa dos fatos, em virtude de seu declarado amor à pátria portuguesa. Sobre Gaspar van Baerle, contudo, o autor oitocentista considera uma obra de exímia latinidade e de descrição mais acertada. Embora essa comparação diga mais do tempo do Barão que do século XVII, é importante referência para os autores que escreveram sobre o domínio holandês sobre as Capitanias do Norte, como Evaldo Cabral de Mello e José Golsalves de Mello.

41. Possivelmente, a imagem de rosto do livro de Van $\mathrm{Ba}-$ erle foi gravada por Theodor Matham (1606-1676), a julgar pela primeira imagem de Nassau conhecidamente desenhada por este ilustrador. Durante a obra, se encontram mapas e paisagens de Frans Post (1612-1680). frontispício deriva de três palavras latinas: frontis, hominis e inspectio. ${ }^{38}$ Dessa forma, o dicionarista relaciona rosto, homem e inspeção (ou o ato de olhar atentamente), ligando-se ao campo semântico levantado por outro dicionarista, desta vez do século XVII. Sebastián de Covarrubias y Orozco, em seu Tesoro da Lengua Castellana, não dicionarizou "frontispício", no entanto a palavra aparece no verbete "frente", onde também é relacionada com fachada arquitetônica. Lembrando que a origem comum das palavras é a latina "frons", e usando Aristóteles e a Bíblia, Covarrubias afirma que: "en la frente trae el hombre mucho de lo que tiene en el animo". ${ }^{39}$ Portanto, o frontispício é pensado como sendo a síntese de um estado. $\bigcirc$ que então representa o rosto do argumento de Brito Freyre e o que podemos visualizar em uma gravura realizada pelo francês Jean Berain (1637-171 1 1)?

Como é explicitado por Freyre, pelo menos um detalhe do frontispício de sua obra foi pensado para ser uma resposta à inscrição de uma das gravuras mais significativas do período de dominação flamenga no Brasil. O debate com a obra começava já pela críica ao frontispício, o que aponta a significância da circulação das imagens e a relação de diálogo entre elas. ${ }^{40}$

\section{OITO ANOS NO BRASIL}

A imagem que abre a obra Rerum per Octennium in Brasilia se assemelha a uma grande guirlanda constituída por lauréis de escudos, frutas e anjos. Ao centro há um pedestal que sustenta um brasão encimado por uma coroa. Ao lado direito está um canhão com munições (referência às guerras empreendidas pelos batavos), enquanto do lado esquerdo estão âncoras e objetos náuticos (referência às habilidades marítimas que identificavam os holandeses no período). Em comparação ao frontispício do Nova Lusitânia, o Rerum per Octennium in Brasilia congrega mais elementos iconográficos que preenchem de forma mais uniforme todo o espaço da página.

Assinando sua obra em Amsterdã, em 20 de abril de 1647, Caspar van Baerle (1584-1648) - ou Gaspar Barléus/Barléu - assim explicou a imagem criada para o frontispício (figura 3) de Rerum per Octennium in Brasilia ${ }^{41}$ (História dos feitos recentes praticados durante oito anos no Brasil): 


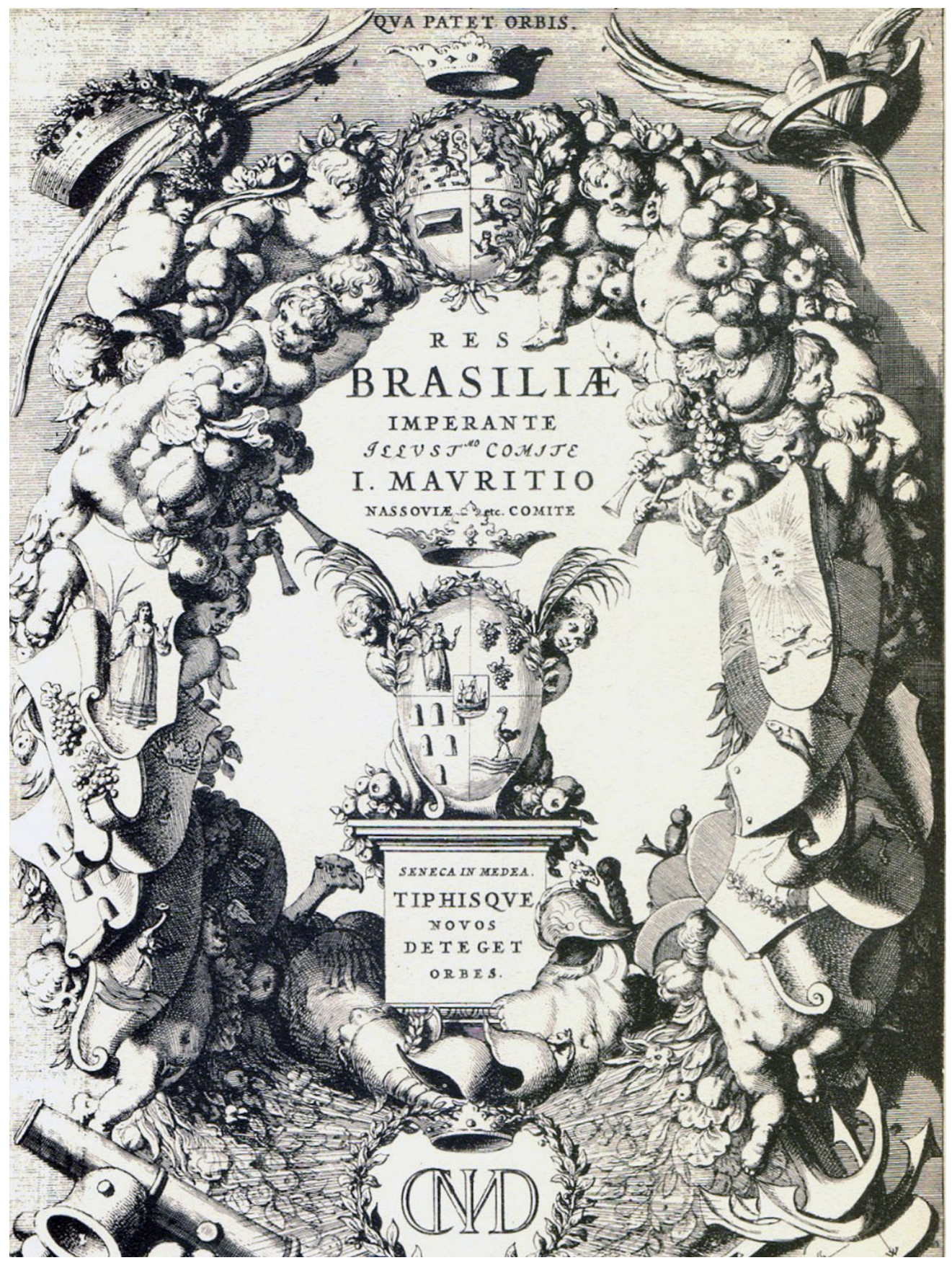

42. Cf. Barléu (1940)

Figura 3 - Frontispício do livro Rerum per Octennium in Brasilia, de Gaspar Barléu. ${ }^{42}$ 


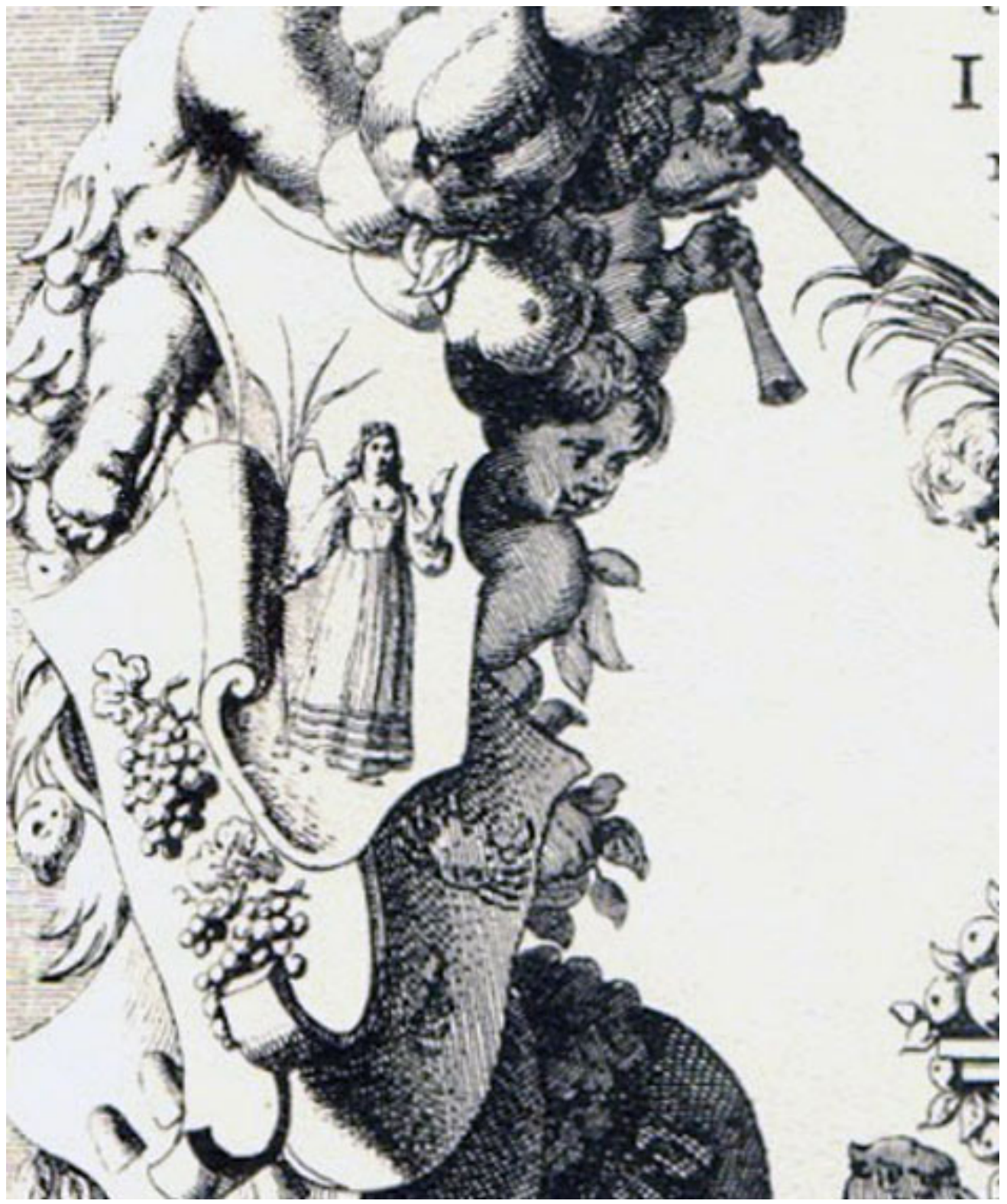

Figura 4 - Detalhe dos escudos. ${ }^{43}$

Os lauréis que, na parte superior, encerram no centro os leões, quiseram assim aludir ao seu titular:

Fulge, de um lado, a coroa mural, que se confere em recompensa das portas entradas; do outro, adorna, por cima, os esporões dos navios o prêmio com que se honram as vitórias navais.

A virgem pernambucana mira os seus olhinhos, e, graciosa, ergue a mão, a qual segura uma cana. (Figura IV) 
Próxima, a fecunda ltamaracá exibe os seus nectários racimos e os magníficos dons do próprio solo.

Junto a ela, a Paraíba põe nas formas o dulcíssimo açúcar e o torna grato aos povos.

O avestruz, errante habitador do Rio Grande, foge correndo, e falsamente imagina que se the dá de comer.

Destarte se ufana o Novo Mundo com os brasões batavos, e, sob o govêrno de Maurício, floresce-the a gleba feraz. As gentes que a terra distingue defende-as um só Chefe. E a Nau de Marte sulca as águas ocidentais, fazendo conhecidos os seus mercantes e os senhores do mar.

Em frente pasma-se o Sol ante as armas, ainda que violentas.

Tu, Sergipe, pões em face de tuas moradas as flamas de Febo, e sozinho queres ser chamado de el Rei.

Teus são, Iguaraçu, os caranguejos.

A ti, Porto Calvo, aprazem os cimos: ali estás sobranceiro, ó tu, que deves ser temido daquelas cumeadas.

gênero escamígero mergulha-se nas rédias das Alagoas.

Contra Serinhaém relincha o belicoso corcel.

Crava a âncora na areia os dentes entravados e quer se nos deem ali reinos diuturnos.

A bússola aponta o Ocidente, mas não olha para o Levante. Por quê? Porque reina cada um em plagas distintas.

A fama, que vês soprar os clarins e as tubas, mostra não o esforço mas o ar de quem apregoa tão grandes cousas. ${ }^{44}$

Essas "invenções" tinham uma intencionalidade clara, assinalada mais abaixo, quando se faz dedicatória ao Conde Maurício de Nassau, principal personagem do livro: "Quando, após alguns séculos, os indígenas, o português e o bárbaro virem, por todas as províncias, os brasões que lhes destes; quando virem os domínios holandeses por vós dilatados e engrandecidos, hão de memorar o poder, a prudência e a felicidade do General. "45 Podemos concluir que a fama, portanto, está aqui em jogo. Além disso, no século XVI, conforme mostrou o historiador Romain Descendre, foi gestado um pensamento político que perdurou: o de que todos os Estados que desejassem se perpetuar "deveriam alargar sua dominação territorial" ${ }^{46}$ Complementamos, pois é através dessa afirmação que se verifica a necessidade da vulgarização dos feitos além-mar entre os Estados modernos que se encontravam então em constante disputa política na Europa do período. Vulgarização esta muito bem empreendida por livros e, particularmente,
44. Barléu (1940, página sem número). A obra original de van Baerle, em latim: BAERLE, Caspar van. Rervm per octennivm in Brasilia. Et alibi nuper gestarum, sub praefectura illustrissimi comitis I. Mavritii Nassoviae, Ec. comitis, nunc Vesaliae gubernatoris \& Equitatus Foederatorum Belgii Ordd. sub Avriaco ductoris, bistoria. Amsterdam: Typographiae Joannis Blaev, 1647.

45. Barléu (Op. Cit., p. XII).

46. Descendre (2015, p. 63). 
com a ajuda de imagens que conectavam territórios e temporalidades afastadas, dando a entender que os domínios de determinado Estado estavam sempre em crescimento.

Na ekphrasis de Rerum per Octennium in Brasilia, nota-se também a referência a "nau de Marte", o deus romano da guerra. Não é a única referência clássica nessa obra, pois os territórios são assim comparados: "Atenas, Lacedemônia, Cartago, Roma, o Lácio, as Gálias e Germânia constituem o assunto dos escritores gregos e romanos. Olinda, Pernambuco, Mauriciópole, Itamaracá, Paraíba, Luanda, S. Jorge da Mina, o Maranhão, nomes desconhecidos dos antigos, serão o nosso tema." Para Barléu, João Maurício de Nassau era digno de ser comparado aos heróis da Antiguidade: "Seguindo-lhes o exemplo, fostes no Novo Mundo qual Metelo nas Gálias, Mário na África, na Germânia Druso e na Panônia Trajano. Assim como estes inscreveram em suas colunas os triunfos contra os estrangeiros, assim também vós havíeis de gravá-los nos ânimos e nos fastos da Holanda." Para encimar o frontispício foi escolhido o lema de Nassau, qua patet orbis, lema que, como ressaltamos, foi alvo de Brito de Freyre (figura 5).

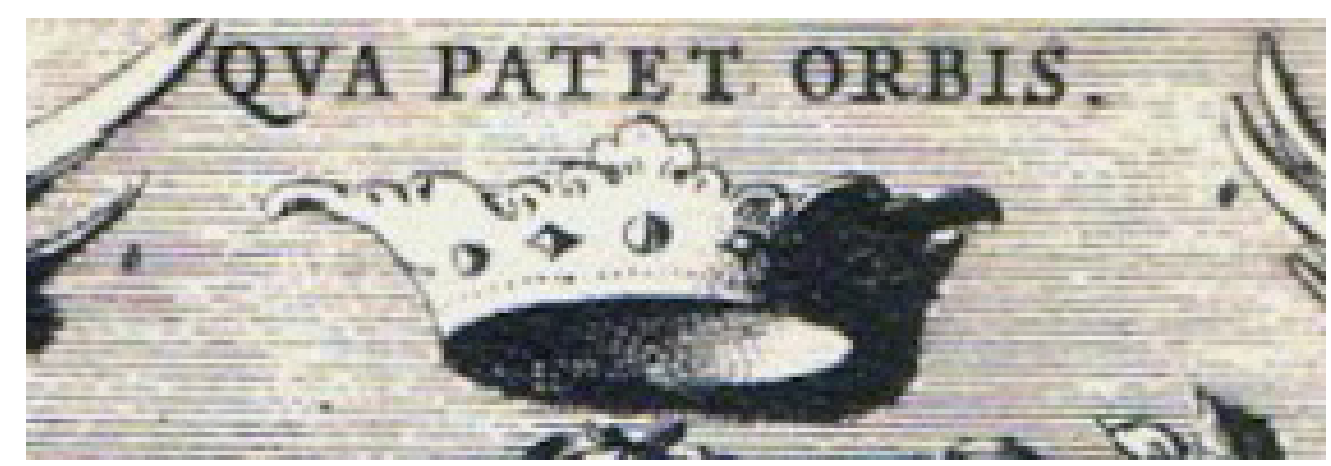

Figura 5 - Detalhe da coroa e do lema holandês presente no Rerum per octennivm in Brasilia. ${ }^{47}$

\section{ASTREA EM PERNAMBUCO}

Na escolha da máxima em latim que coroaria seu frontispício, Francisco de Brito Freyre também faz uma referência à antiguidade clássica. Voltemos então ao frontispício de Nova Lusitânia e sua inscrição. Ele está sobre o brasão da dinastia de Bragança que por sua vez é encimado por uma coroa que está 
à frente de um globo terrestre, e seu dizer é o seguinte: caelo demititur alto (figura 6). Identificamos como sendo parte de um trecho da quarta Écloga de Virgílio. A tradução completa é a que segue:

Do Cúmeo Vaticínio eis chega a idade;

Grande ordem já de séculos decorre:

Torna Satúrnios tempos, torna a Virgem;

Do céu nova progênie enfim descende. ${ }^{48}$

Jacques Berlioz já enfatizara a relevância de Virgílio em um gênero narrativo muito presente entre as práticas de escrita da ldade Média: o exemplum. ${ }^{49}$ Nesse trecho do frontispício, a exemplificação de uma nova era é feita pela mobilização de uma figura muito conhecida nas cortes do Antigo Regime, e que Virgílio associa ao retorno de um tempo: Astrea. Com o fim da ldade de Ouro, essa deusa foi a última dos imortais a abandonar a terra. Representando a justiça e a fortuna, ela marcou presença nas obras do Século de Ouro espanhol, como em Calderón de la Barca. 50 "Cúmeo" faz referência a cidade de Cumas, local do oráculo de uma sibila, profetisa de Apolo; iá "Satúrnios tempos" diz respeito ao tempo cíclico das profecias, um retorno ao Deus da primeira Era, ou seja, Saturno. Portanto, a frase "Do céu nova progênie enfim descende", escrita em latim, emoldurada por frutas, como abacaxis, e tendo abaixo fumo, cana-de-açúcar e outros produtos, numa verdadeira arcádia tropical, ${ }^{51}$ é bem apropriada ao "Nova Lusitânia" do título, já que Brito Freyre faz referência em sua obra não só à reconquista do território aos holandeses, mas à própria Restauração portuguesa do domínio castelhano interpretado, muitas vezes, como um novo tempo. Outrossim, é preciso ressaltar que Astrea possuía relação com o conceito de justiça, muitas vezes sendo usada alegoricamente nos discursos políticos ou até mesmo de forma mais direta ainda, como o fez Dante Alighieri em seu De Monarchia, no início do século XIV:

Além disso, o mundo está perfeitamente disposto quando nele a justiça é exercida em toda a sua plenitude. Por isso Virgílio, desejando celebrar aquela época que parecia renascer dos tempos dele, cantava nas Bucólicas: "Já a Virgem regressa e voltam os reinos de Saturno". "Virgem", de fato, era chamada a justiça que era também denominada Astreia. "Reinos de Saturno" eram definidos aqueles tempos extraordinários, chamados também "tempos áureos". A justiça em seu mais alto grau só existe sob o monarca. Para a melhor ordenação do mundo é necessária, portanto, a monarquia ou o império. ${ }^{52}$
48. Virgílio (2008, p. 87).

49. Cf. Berlioz (1985).

50. Cf. Armas (1986).

51. É importante lembrar da clássica análise de Sérgio Buarque de Holanda das frutas tropicais nos livros e tratados da Idade Moderna. Cf. Holanda (2000).

52. Alighieri (2017, p. 43). 
53. Cf. Freyre (Op. Cit.).

54. Cf. Yates (1999).

55. Freitas (1959, p. 224).

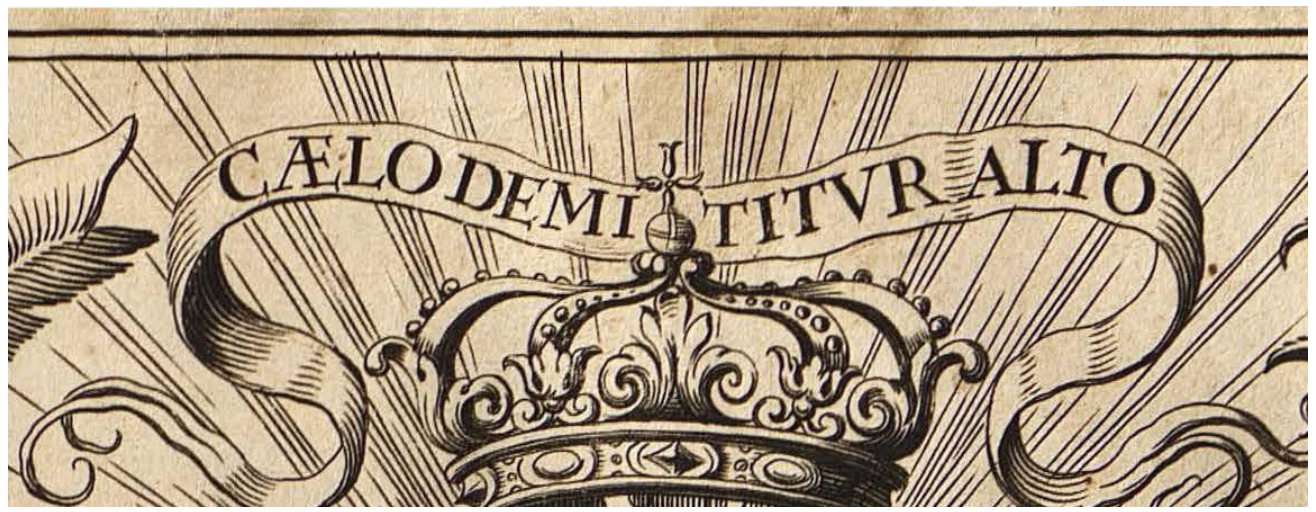

Figura 6 - Detalhe da coroa e da resposta ao lema holandês, presente no livro Nova Lusitânia. ${ }^{53}$

\section{CONSIDERAÇÕES FINAIS}

É arriscado concluir que Brito Freyre usou as armas da monarquia portuguesa junto ao mote de Virgílio pensando justamente nas ideias de Dante? Só podemos dizer que é provável que assim o tenha feito, pois em seu texto não há indicação da leitura dessa obra. No entanto, vale salientar que Frances Yates destacou a presença do pensamento do poeta florentino e, através deste, da Astrea na cultura política Ibérica. ${ }^{54}$ Mais seguro é afirmar a leitura que Brito Freyre fez de Frei Serafim de Freitas, citado em Nova Lusitânia por conta de sua conhecida querela com o holandês Hugo Grotius sobre o direito de navegação dos mares. Em seu sumário, precisamente no capítulo VIII, Freitas cita o Poeta e sua profecia: "os portugueses são notabilíssimos nas artes navais. As Sibilas, Virgílio e Sêneca vaticinaram a navegação dos nossos para a Índia". A profecia é mais específica, pois cita a Écloga III: "haverá então um outro Tífis, e uma nova Argos que levará os escolhidos heróis". Freitas também cita Sêneca, o segundo ato de Medea: "Séculos virão em tardios anos em que o oceano abrandará os seus vínculos, surgirá um grau de terra, e Tífis descobrirá Novos Orbes. " 55 Já Brito Freyre, ao falar da antiguidade das terras descobertas e dos feitos navais realizados pelos portugueses, afirma que "até as fantasias dos Poetas, alegam por testemunhas da verdade, citando Sêneca onde falam suas tragédias, além da última Thule a nova terra". No frontispício, está o território "além da última Thule", os "novos orbes", "a Nova Lusitania" com o típico tatu na terra e um monstro no mar, e com as colunas de Hércules quebradas, um arcaico marcador dos espaços terrestres adotado pelos castelhanos no tempo de Carlos V, e, claro, um navio ostentando bandeiras dos Braganças e com as amarras soltas. Concluímos que tanto a alegoria de abertura da Nova Lusitânia, como a da Rerum per Octennium in Brasilia conectam 
temporalidades (passado, presente, futuro), criando uma eficácia visual para o gênero de que tratavam: o histórico. No discurso presente nas obras, para um melhor convencimento políitico, acionar apenas uma temporalidade não era suficiente. 


\title{
REFERÊNCIAS
}

\author{
FONTES IMPRESSAS
}

BARLÉU, Gaspar. História dos feitos recentemente praticados durante oito nos no Brasil e noutras partes sob o governo do ilustríssimo João Maurício Conde de Nassau Erc., ora Governador de Wesel, Tenente-General de Cavalaria das Províncias-Unidas sob o Príncipe de Orange. Tradução e anotações de Cláudio Brandão. Rio de Janeiro: Serviço Gráfico do Ministério da Educação, 1940.

BLUTEAU, Rafael. Vocabulario Portuguez e latino. Coimbra: Collegio das artes da Companhia de Jesus, 8 v., v. 4, 1713.

COVARRUBIAS Y OROZCO, Sebastián de. Tesoro da Lengua Castellana, o Española. Madrid: Melchior Sanchez, 2 v., v. 2, 1673.

ERICEIRA, Conde de, Dom Luiz de Menezes. História de Portugal Restaurado. Lisboa: na Officina de João Galrão, 1679.

FREITAS, Frei Serafim de. Do Justo Império Asiático dos portugueses. Lisboa: Instituto de Alta Cultura, 2 v., v. 1, 1959.

FREYRE, Francisco de Brito. Nova Lusitânia, História da Guerra Brasílica. Lisboa: na Officina de João Galrão, 1675.

GALHEGOS, Manuel de. Templo da Memoria. Lisboa: Craeesbeeck, v. 3, 1635.

LIVROS, ARTIGOS E TESES

ALBERTI, Leon Batista. Da pintura. In: LICHTENSTEIN, Jacqueline (Org.). A pintura: textos essenciais. São Paulo: Editora 34, 2004.

ALIGHIERI, Dante. Monarquia. São Paulo: Lafonte, 2017. 
ARMAS, Frederick A. de. The return of Astrea: an Astral imperial mith in Calderón: University Press of Kentucky, 1986.

BAXANDALL, Michael. Padrões de intenção: a explicação histórica dos quadros. São Paulo: Companhia das Letras, 2006.

BERLIOZ, Jacques. Virgile dans la littérature des exempla (XIIIe-XVe siècles) In: Lectures médiévales de Virgile. Actes du colloque de Rome (25-28 octobre 1982). Rome: École Française de Rome, 1985, p. 65-120.

BREDEKAMP, Horst. Thomas Hobbes's Visual Strategies. In: SPRINGBORG, P. (Org.). The Cambridge Companion to Hobbes's Leviathan. Cambridge: Cambridge University Press, 2007. p. 29-60.

CURTO, Diogo Ramada. O discurso político em Portugal, 1600-1650. Lisboa: Universidade Aberta, 1988.

DESCENDRE, Romain. A politização do mundo. Campinas, SP: Unicamp, 2015.

DIDI-HUBERMAN, Georges. A imagem sobrevivente: história da arte e tempo dos fantasmas segundo Aby Warburg. Rio de Janeiro: Contraponto, 2013.

FLETCHER, Angus. Allegory. The Theory of a Simbolic Mode. Ithaca: Cornell University, 1990.

GINZBURG, Carlo. Medo, reverência, terror. Quatro ensaios de iconografia política. São Paulo: Companhia das Letras, 2014.

HANSEN, João Adolfo. Agudezas seiscentistas e outros ensaios. São Paulo: Edusp, 2019.

HANSEN, João Adolfo. Alegoria. Construção e interpretação da metáfora. São Paulo: Atual, 1986.

HANSEN, João Adolfo. Barroco, Neobarroco e outras ruínas. Teresa - Revista de literatura brasileira, n. 2, p. 10-68, 2001.

HERRERA MORILLAS, José Luis. Aspectos artísticos del fondo antiguo digital de la Universidad de Sevilla: los fronstispicios del siglo XVI. Anales de Documentación, v. 18, n. 2, p. 3-27, 2015. 
HOLANDA, Sérgio Buarque de. Visão do paraíso: os motivos edênicos no descobrimento do Brasil. São Paulo: Brasiliense, 2000.

MARTINS, Maria Teresa Payan. Marcar e falsificar: o caso dos impressores da família Galrão. Cultura, v. 33, p. 1-17, 2014.

MELLO, Evaldo Cabral de. Nassau: governador do Brasil holandês. São Paulo: Companhia das Letras, 2006.

MELLO, José Gonsalves de. Brito Freyre, sua História e Pernambuco. Posfácio. In: FREYRE, Francisco de Brito. Nova Lusitânia: História da guerra brasílica. Recife: Secretaria de Educação e Cultura, 1977.

RANCIÈRE, Jacques. O destino das imagens. Rio de Janeiro: Contraponto, 2012.

REDONDI, Pietro. Galileu herético. São Paulo: Companhia das Letras, 1991.

SANCHEZ, Talita de Jesus Noronha. Uma Iconografia Profética da Restauração: a imagem de Ourique e as disputas políticas nas gravuras de 1632 a 1668. 2018. 187 f. (Dissertação de Mestrado) - Programa de Pós-Graduação em História da Escola de Filosofia, Letras e Ciência e Ciências Humanas da Universidade Federal de São Paulo, Guarulhos, 2018.

SKINNER, Quentin. Hobbes e a liberdade republicana. São Paulo: Unesp, 2010.

VARNHAGEN, Adolfo de. Historia das lutas dos Holandezes no Brazil: desde 1624 a 1654. Lisboa: Typografia de Castro Irmão, 1872.

VIRGÍliO. Bucólicas. Campinas: Unicamp; São Paulo: Ateliê Editorial, 2008.

WAGNER, Roy. A invenção da cultura. São Paulo: Cosac Naify, 2010.

WAIZBORT, Leopoldo. Apresentação. In: WARBURG, Aby. Histórias de fantasmas para gente grande: escritos, esboços e conferências. São Paulo: Companhia das Letras, 2015. p. 7-22.

XAVIER, Ângela Barreto. "El Rei aonde póde, E não aonde quer". Razões da política no Portugal seiscentista. Lisboa: Edições Colibri, 1998.

YATES, Frances. Astraea. Londres/Boston: Rotledge \& Kegan Paul, 1999. 
Artigo apresentado em 26/08/2019. Aprovado em 25/03/2020.

\section{(cc)BY}

All the contents of this journal, except where otherwise noted, is licensed under a Creative Commons Attribution License 